\title{
Does Consultation Time Influence Patient Perception of Provider Communication Style, Patient Satisfaction And Word of Mouth Recommendation In India? A Mediation Analysis
}

PAYAL MEHRA

Communication IIM Lucknow Prabandhnagar Off Sitapur Road, Lucknow 226024, India

Correspondence: payal@iiml.ac.in

\begin{abstract}
Background In medically underserved developing countries such as India, the length of the consultation is often compromised; providers, it appears, have lost their natural empathetic tendencies and try to substitute talk with techniques and procedures. Despite this, surprisingly, patient satisfaction is high in India. This raises questions on the importance of understanding how patients feel about the clinical consultation length and the way it affects their satisfaction. In this context, this study analysed if the time spent with the patient predicted different changes to patient satisfaction with the provider and word of mouth recommendation.
\end{abstract}

Methods This cross sectional study comprised a sample of working Indian adults $(\mathrm{N}=501)$, completing communication competence measures and indicating their satisfaction and word of mouth recommendation potential. The four step Baron and Kenny's model of mediation analysis, apart from the GLM and factor analysis, was used for the analysis.
Results Findings showed that the communication style of the providers positively influenced the health outcomes such as patient satisfaction and word of

mouth recommendation, and the length of direct consultation time mediated this relationship. Gender wise, male patients were more likely to complain about poor communication competency of the providers and less consultation time than female patients

Conclusion We conclude that patients positively associate a longer clinical consultation time with empathetic and competent providers and be willing to recommend him/her to others. However due to extreme paucity of qualified providers in India, patients generally ignore or suffer problems related to time or communication style.

Keywords: Patient satisfaction, India, Consultation length, Outpatient clinics, Communication style, Word of mouth 


\subsection{Introduction}

Patient provider communication is the core of health care service. Poor communication results in missed opportunities for both patient and provider. [1] Poor patient-provider communication is evident when patients with chronic health issues failed to use their prescriptions and do little to communicate the same to their physicians. [2,3] One research pointed out those providers appeared to have lost their natural empathetic tendencies and (were) inclined to substitute techniques and procedures for talk. [4]

In India, patients far outnumber the providers, and providers end up compromising on the quality of the communication to serve the long queues in the waiting area of the outpatient clinic. The health sector in India faces an acute shortage with only approximately 1.54 million doctors and 2.4 million nurses to match the global average. [5]

\subsection{Literature Review}

In their review of literature on doctor-patient communication Fong Dip and Longnecker conclude that in reality doctors overestimate their proficiency in communication. [6] Citing doctors' avoidance behavior, discouragement of collaboration, and patient resistance as the chief barriers to an effective doctor patient communication, the authors recommend large scale communication skills training of doctors to remedy the issue.

Researchers have also questioned the social interaction model whereby a patient should not evaluate the quality of medical care solely on the basis of the doctor's communication style. Proposed by Ben-Sira it assumes that the rational thinking patient will care about the doctor's communication style only if he/she is diagnosed with a serious illness, when visiting the doctor for the first time, or more importantly, when he/she is given less consultation time. [7] This viewpoint was widely criticized by Buller and Buller. [8] The latter report that greater time spent did not imply more number of satisfied patients.

In their reinterpretation of past models of doctor patient interaction, Agarwal and Murinson propose a new model of communication, thereby representing a significant shift from the traditional modes of communication. [9] Understanding that the patient today is more informed and somewhat better equipped with medical knowledge, their model exhorts the doctors to be more mindful of effective communication for overall patient satisfaction.

Studies show that a patient's in-clinic experience was vastly improved when providers demonstrated empathy and active listening skills. [10,11,12,13] For example, Roter (2000) described effectiveness of provider communication skills as being akin to a 'therapeutic' experience; small talk and informal conversations boosted the patients' sense of participation and encouraged them to ask open-ended questions. $[14,15,16,17]$

In a similar study, Flocke, Miller and Crabtree (2002) tested different interaction styles with respect to primary care and the duration of the visit, and concluded that satisfied patients reported that their providers were more people-focused as they granted them the longest visits.[18] Studies also revealed that when providers bypassed verbal and vocal clues provided by the patients, the in-clinic discussion became less patient-centered and more authoritarian in nature. [19]

Extant research has sought to link consultation time, patient satisfaction, and patient-provider interaction. [20] Results are mixed in this 
regard. While longer consultation time was associated with enhanced communication and patient satisfaction in some studies, other studies such as one by Buller and Buller (1987) show that patients respond poorly to extended consultation time. $[21,22,23,24,25]$

\subsection{Research Objective}

In view of the contradictory research opinions above, it makes sense to examine the role of consultation length and its mediating effects on the relationship between the communication style of the provider and the dependent (outcome) variables (patient satisfaction, and positive word of mouth recommendation) in the context of a medically underserved country.

Based on the literature review, a hypothesized model was developed where communication style was defined as the main independent variable of the study (see Figure 1). The two dependent variables were operationalized by a single question on an 11-point scale: Are you satisfied with the provider? Will you recommend the provider to others? Consultation length was treated as a mediator between communication style and patient satisfaction.

The hypothesized research model is presented below:

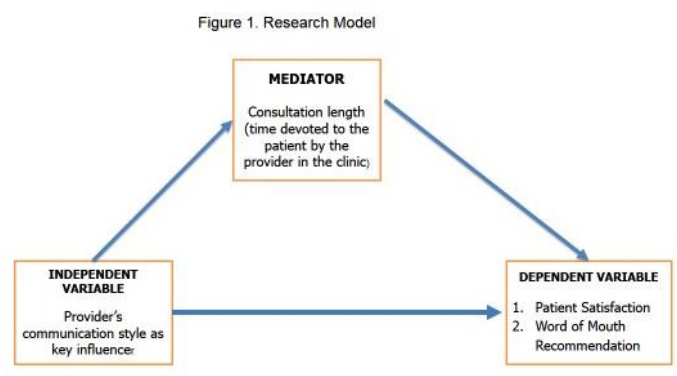

Figure 1: The Hypothesised Research Model

\subsection{Methods}

Based on the above, two goals were defined: a) to test the contribution of communication style of the provider as a predictor of patient satisfaction; b) to test whether the length of consultation time mediated the relationship between communication style and patient satisfaction.

3.1 Study site. This study was conducted in Lucknow, located in Uttar Pradesh state of North India. It has a population of $212,744,738$ with a literacy rate of $67.68 \%$ (visit http://www.uttarpradeshstat.com/health/16/ allopathy/29091/healthcentres19812016/449 461/stats.aspx). As of date, the state has 3692 operational PHCs (primary healthcare centres) with 2861 doctors.

3.2. Participants and procedures. A cross sectional survey of 505 patients was carried out in 33 select outpatient clinics and hospitals using the exit interview method duly following the research protocol of obtaining the permission of the providers and the patients. Statistical analysis was performed using the Factor analysis, General Linear Model and Mediation tests.

3.3 Study design and data collection. The patients were asked to answer a questionnaire with clinical, socio-economic, demographic information and communication and related assessment items in a structured interview using a Likert-type scale. The length of the consultation time was measured by giving five options to the patients (5-10 minutes; $11-15$ minutes; 16-20 minutes; 21-25 minutes; 26 minutes and above). A pilot study of the first 100 patients was conducted where few repetitive and leading questions were deleted.

3.4 Characteristics of the sample. The sample comprised $52 \%$ male and $48 \%$ female 
patients. $18 \%$ patients were first time visitors. Close to $53 \%$ were consulting the provider on recommendation from a known person. $74 \%$

patients were from urban localities, while $26 \%$ came from the surrounding rural districts and villages. $50 \%$ of the patients required treatment for chronic illnesses, and $50 \%$ for acute illnesses or injury. $48 \%$ stated that less than 15 minutes' consultation time was allotted to them (this included $18 \%$ of the patients who said that their consultation time was less than 10 minutes). Only $2 \%$ of the providers used email to fix appointments and schedule visits. Table 1 depicts the descriptive analysis of time spent with the provider and outcome analysis (patient satisfaction and words of mouth recommendation)

Table 1: Descriptive analysis: time spent with the provider and outcome analysis

\begin{tabular}{|l|l|l|l|l|l|l|l|}
\hline $\begin{array}{l}\text { Item } \\
\text { description }\end{array}$ & $\begin{array}{l}\text { Time spent with } \\
\text { the provider, in } \\
\text { minutes, in a } \\
\text { single interaction }\end{array}$ & $\mathbf{N}$ & $\begin{array}{l}\text { Mean } \\
\text { score }\end{array}$ & $\begin{array}{l}\text { Std. } \\
\text { Deviatio } \\
\mathbf{n}\end{array}$ & $\mathbf{F}$ & $\begin{array}{l}\text { Sig of the } \\
\text { ANOVA }\end{array}$ \\
\hline \multirow{2}{*}{$\begin{array}{l}\text { I would } \\
\text { surely } \\
\text { recommend } \\
\text { the provider }\end{array}$} & 1.00 & $0-5$ & 63 & 6.7778 & 2.01162 & 22.305 & .000 \\
\cline { 2 - 8 } & 2.00 & $6-10$ & 36 & 8.1389 & 1.67593 & 27.230 & .000 \\
\cline { 2 - 8 } & 3.00 & $11-15$ & 158 & 8.2911 & 1.65227 & 81.988 & .000 \\
\cline { 2 - 8 } & 4.00 & $16-25$ & 241 & 8.7303 & 1.23738 & 2.411 & .000 \\
\cline { 2 - 8 } & 5.00 & $>26$ & 7 & 9.7143 & .95119 & & .066 \\
\cline { 2 - 8 } & Total & 505 & & 8.3208 & 1.64029 & & .000 \\
\hline \multirow{4}{*}{$\begin{array}{l}\text { I am wholly } \\
\text { satisfied with }\end{array}$} & 1.00 & $0-5$ & 63 & 6.4603 & 2.08548 & 28.985 & .000 \\
\cline { 2 - 8 } the provider & 2.00 & $6-10$ & 36 & 8.1389 & 1.58840 & 24.028 & .000 \\
\cline { 2 - 8 } & 3.00 & $11-15$ & 158 & 8.3481 & 1.39118 & 99.740 & .000 \\
\cline { 2 - 8 } & 4.00 & $16-25$ & 241 & 8.6680 & 1.29332 & 5.400 & .000 \\
\cline { 2 - 8 } & 5.00 & $>26$ & 7 & 9.1429 & 1.86445 & & .000 \\
\cline { 2 - 8 } & Total & 505 & & 8.2614 & 1.62782 & & .000 \\
\hline
\end{tabular}

Provider means the Doctor. Measured on an 11-point scale. ANOVA is significant at $p<.05$

3.5 Measures. Factor Analysis and Mediation Analysis. SPSS v16 was utilized for the statistical analysis of the results. The Factor analysis yielded two components: The provider's communication style and expertise (which included empathy, response to questions, listening ability, clarification of

doubts, summarizing ability, additional information and explanation, attention and eye contact) and the 'health system infrastructure component' (reputation gained from availability of state-of-the-art medical facilities, seating space, and presence of a computerized environment at the clinic).
Thereafter, the General Linear Model (GLM), also known as the MANOVA, was conducted to identify the key variables that contributed the most to the model; this in turn, was utilized to test the Mediation hypothesis.

The GLM was controlled for gender (Supplementary Data Tables S1 and S2). Results of the GLM show that the value of the Wilks lambda was the lowest and that the value of the Hoteling trace was the highest in the case of the core competence of the provider ( $p$ value $<0.05$ ). This indicated that that only Factor 1, the 'provider's core competence' contributed significantly to the 
model. Therefore, only Factor 1 could be used for the mediation tests (Supplementary Data Tables S1-S5).

\subsection{Model estimation and results for} determining reliability and validity. A partial least square (PLS) approach was used to test the validity of the proposed model and the hypotheses [26] (Hair et.al.,2014). PLS is recommended when structural model is complex and assumptions about normality of data are not required. The measurement model was evaluated by assessing the composite reliability and convergent validity. Figure 1.1 indicated the measurement model for this research.

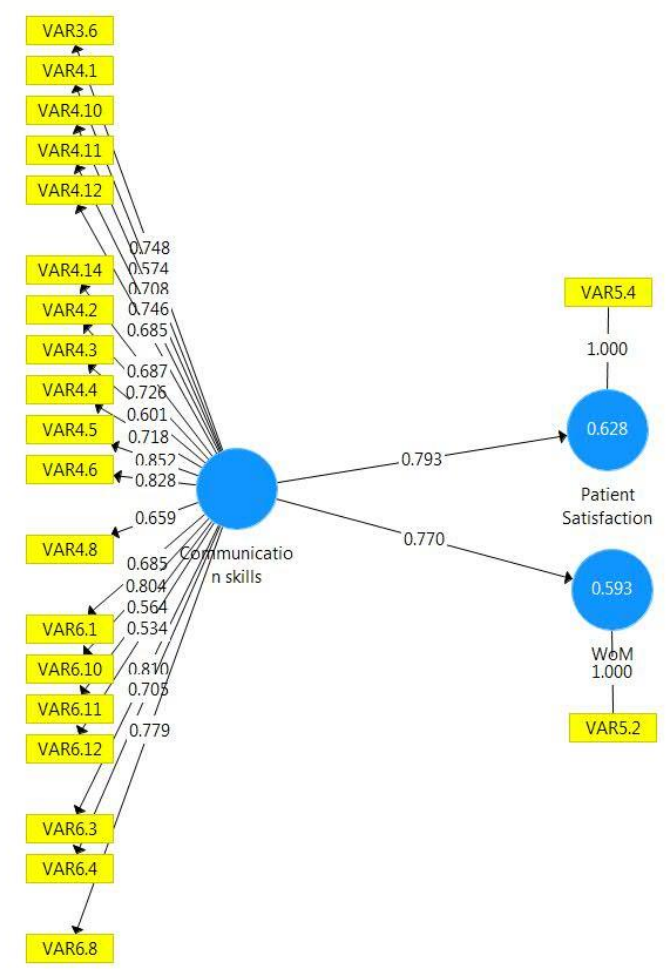

Figure 1.1: The measurement model

The outer loadings of the constructs were found to be statistically significant (see supplementary files for details on variables). The value of Cronbach's alpha was high (0.945), and above the 0.6 cut off rate prescribed by Nunnally and Berstein. [27] Internal consistency was measured by the composite reliability value, which was 0.950 (above the acceptable lower limit of 0.7).

To validate the model, the convergent validity approach was selected. The results of the measurement model show that the factor loadings exceeded the recommended value of 0.5 and that the composite reliability (CR) value was above 0.7. The AVE values were above the recommended value of 0.5 (27) and hence the convergent validity of the communication and expertise construct was established.

\subsection{Results}

\subsection{Factor Analysis and the General Linear Model (GLM).}

The Factor Analysis and the General Linear Model (GLM) identified the key factors that contributed the most to the model, and these, in turn, were utilized to test the Mediation hypothesis (see Table 2). Patients rated two factors as most important: The provider's 'core competence' component (provider expertise

and communication style) and the 'health system infrastructure component' (reputation gained from availability of state-of-the-art medical facilities, seating space, and a computerized environment at the clinic). 
Table 2: General Linear Model: results of multivariate tests to test which factor contributes most to the model

\begin{tabular}{|c|c|c|c|c|c|c|}
\hline \multicolumn{2}{|l|}{ Effect } & Value & $\mathbf{F}$ & Hypothesis df & Error df & $\begin{array}{l}\text { Test of } \\
\text { significan } \\
\text { ce. }\end{array}$ \\
\hline \multirow[t]{4}{*}{ Intercept } & Pillai's Trace & .972 & $8.545 \mathrm{E}^{\mathrm{a}}$ & 2.000 & 500.000 & .000 \\
\hline & Wilks' Lambda & .028 & $8.545 \mathrm{E}^{\mathrm{a}}$ & 2.000 & 500.000 & .000 \\
\hline & Hotelling's Trace & 34.179 & $8.545 \mathrm{E}^{\mathrm{a}}$ & 2.000 & 500.000 & .000 \\
\hline & Roy's Largest Root & 34.179 & $8.545 \mathrm{E}^{\mathrm{a}}$ & 2.000 & 500.000 & .000 \\
\hline \multirow[t]{2}{*}{ FAC1_1 } & Pillai's Trace & .551 & $3.069 \mathrm{E} 2^{\mathrm{a}}$ & 2.000 & 500.000 & .000 \\
\hline & Wilks' Lambda & .449 & $3.069 \mathrm{E} 2^{\mathrm{a}}$ & 2.000 & 500.000 & .000 \\
\hline \multirow{2}{*}{$\begin{array}{l}\text { Core } \\
\text { competence of } \\
\text { the provider }\end{array}$} & Hotelling's Trace & 1.227 & $3.069 \mathrm{E} 2^{\mathrm{a}}$ & 2.000 & 500.000 & .000 \\
\hline & Roy's Largest Root & 1.227 & $3.069 \mathrm{E} 2^{\mathrm{a}}$ & 2.000 & 500.000 & .000 \\
\hline \multirow[t]{2}{*}{ FAC2_1 } & Pillai's Trace & .291 & $1.025 E 2^{a}$ & 2.000 & 500.000 & .000 \\
\hline & Wilks' Lambda & .709 & $1.025 \mathrm{E} 2^{\mathrm{a}}$ & 2.000 & 500.000 & .000 \\
\hline \multirow{2}{*}{$\begin{array}{l}\text { Health system } \\
\text { and } \\
\text { infrastructure }\end{array}$} & Hotelling's Trace & .410 & $1.025 \mathrm{E} 2^{\mathrm{a}}$ & 2.000 & 500.000 & .000 \\
\hline & Roy's Largest Root & .410 & $1.025 E 2^{a}$ & 2.000 & 500.000 & .000 \\
\hline \multirow[t]{4}{*}{ VAR6.13 } & Pillai's Trace & .004 & $.898^{a}$ & 2.000 & 500.000 & .408 \\
\hline & Wilks' Lambda & .996 & $.898^{a}$ & 2.000 & 500.000 & .408 \\
\hline & Hotelling's Trace & .004 & $.898^{a}$ & 2.000 & 500.000 & .408 \\
\hline & Roy's Largest Root & .004 & $.898^{a}$ & 2.000 & 500.000 & .408 \\
\hline
\end{tabular}

a. Exact statistic

b. Design: Intercept +FAC1_1 + FAC2_1 + VAR6.13; Kaiser-Meyer-Olkin Measure of Sampling Adequacy=0.868; Sig. 0.000.; $R$ Squared $=.615$ (Adjusted $R$ Squared $=.613$ )

Except for factor 1, the value of the Wilks lambda was too high, indicating that only Factor 1, the 'provider's core competence' component contributed significantly to the model. Results also illustrated that the Hoteling

trace was the highest in the case of the core competence of the provider, and the $p$ value was less than 0.05 . The results suggested that Factor I could be used for the mediation tests
The four steps [28] Baron and Kenny (1986) model was used to assess the possibility of mediation and it confirmed the presence of full mediation. Thus, the null hypothesis was rejected, and consultation length fully

mediated the relationship between provider competency and word of mouth recommendation and patient satisfaction (Figure 2)

\subsection{Mediation analysis}

Figure 2: Results of the mediation analysis 
Figure 2. Mediation analysis (path diagram using the unstandardized coefficients)

Panel A: 'word of mouth recommendation' $(\mathrm{c}=1.170)$ and 'overall patient satisfaction' $(c=1.168)$ (derived from Step 1)

Panel B: c value is derived from Step 4 (0.325 and 0.433)

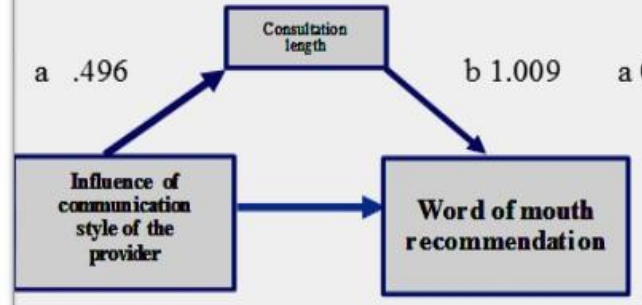

c' 0.325

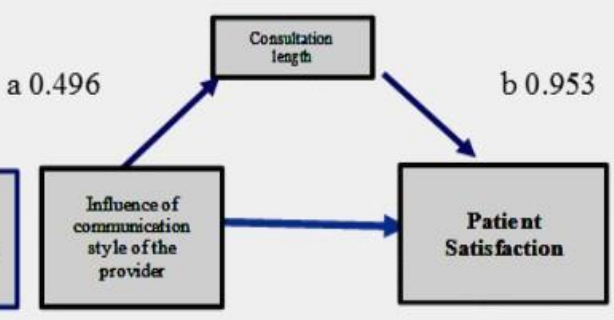

c' 0.433

Table 3: Results of the 4-step mediation analysis

\begin{tabular}{|c|c|c|c|c|c|}
\hline \multirow[b]{2}{*}{ Total Effect } & $\begin{array}{l}\text { Total effect } \\
\text { of } \\
\text { consultation } \\
\text { time }\end{array}$ & $\begin{array}{l}\text { Direct } \\
\text { effect }\end{array}$ & $\begin{array}{l}\text { Mediated effects: } \\
\text { The product of the } \\
\text { Unstandardized }\end{array}$ & $\begin{array}{l}\text { The product of } \\
\text { the standardized } \\
\text { estimates of the } \\
\text { path coefficients } \\
\text { ab }\end{array}$ & Conclusion \\
\hline & $c=1.007$ & & coefficients ab & & \multirow{3}{*}{$\begin{array}{l}\text { Full Mediation } \\
\text { Reason: } \\
\text { The null hypothesis } \\
\text { HO: ab = } 0 \text { using the } \\
\text { unstandardized } \\
\text { coefficients is } \\
\text { rejected. Both } \\
\text { products are greater } \\
\text { than } 0.00\end{array}$} \\
\hline $\begin{array}{l}\text { Patient } \\
\text { Satisfaction }\end{array}$ & & $C^{1}=0.433$ & $\begin{array}{l}a b^{1}=0.496 \times 0.953= \\
0.470\end{array}$ & $\begin{array}{l}a b=1.170 x \\
.953=1.180\end{array}$ & \\
\hline WOM & & $C^{2}=0.325$ & $\begin{array}{l}a b^{2}=0.496 \times 1.009= \\
0.500\end{array}$ & $\begin{array}{l}a b=1.168 x \\
1.009=1.110\end{array}$ & \\
\hline
\end{tabular}

\subsection{Mediation analysis steps.}

First, a regression was run to predict word of mouth recommendation and patient satisfaction from the influence of communication competence of the provider.
Both, word of mouth recommendation and overall patient satisfaction were statistically significant (see Table 3)

In step 2, the mediator was used as the independent variable and both the dependent variables as dependent variables. A regression 
was performed to predict the consultation length from the influence of communication competence of the provider. Following this, a regression analysis was performed to predict the mediating variable (consultation length) from the causal variable (influence of communication competence of the provider on the patient). Finally, a regression analysis was performed to predict the outcome variable (patient satisfaction and word of mouth recommendation) from both the communication competence of the provider, and the consultation length (see Supplementary tables S1-S4 in the appendix for detailed test results).

Mediation analysis effected partitioning of influencing factors in that it partitioned the total effect of empathy and expertise on word of mouth recommendation and satisfaction into a direct effect and a mediated effect. It also partitioned the total effect of influence on word of mouth recommendation into a direct effect and a mediated effect. In addition, it partitioned the total effect of the influence of provider's communication competence on overall patient satisfaction into a direct effect and a mediated effect. Both these were evaluated in terms of standardized/unit-free path coefficients. The unit-free index of strength of the mediated effect (the effect of influence of provider's communication competence on word of mouth recommendation and overall satisfaction at the outpatient clinic through the mediating variable i.e., consultation length), is given by the product of the standardized estimates of the path coefficients ab. For each increase in influence of provider's communication competence, an increase in word of mouth recommendation and patient satisfaction is predicted.

The strength of the direct or non-mediated path from influence factors to
recommendation $\quad$ and satisfaction corresponded to $c^{\prime}$. In other words, for a onestandard deviation increase in influence of provider's communication competence, a 1.009 increase in word of mouth recommendation was predicted through the mediating variable, namely, the consultation length. In addition, a 0.496 increase in word of mouth recommendation was predicted due to the direct effects of the influence factors (effects that were not mediated by consultation length); this corresponded to the $c^{\prime}$ path. The total effect of influence factors on word of mouth recommendation corresponded to path $c$, and the unstandardized coefficient for path $\mathrm{c}$ was 0.325 .

For the unstandardized coefficients of the overall satisfaction, this product was 0.470 . In other words, for a one-standard deviation increases in influence of provider's communication competence, a 0.953 increase in patient satisfaction was predicted through the mediating variable namely, consultation length. In addition, a 0.496 increase in patient satisfaction, due to direct effects of the influence factors (effects that were not mediated by consultation length), was predicted, and corresponded to the $c^{\prime}$ path. The total effect of influence of provider's communication competence on patient satisfaction corresponded to path $\mathrm{c}$, and the unstandardized coefficient for path $\mathrm{c}$ was 0 . 433 (see Figure 2)

\subsection{Discussion}

In this empirical study, evidence indicates that longer consultation length positively influenced the relationship between communication style of the provider and patient satisfaction and word of mouth recommendation. Patients who reported a higher consultation time were also more satisfied with the communicative 
competence of the providers indicating the importance of chat. Conversely, patients satisfied with the communication style of the patients but given less consultation time expressed lower satisfaction, as well as decreased word of mouth recommendation. Patients associated enhanced consultation time with empathy and support in decision making.

Predictably, patient satisfaction, measured on a global scale, was reasonably high, and a large majority of the patients reported that they would recommend the provider that they were consulting. The effect of influence of provider's communication competence on patient satisfaction, in statistical terms, was ' $a=1.170$ ' and '1.165' and was significant based on the $t$ test. This implied that it was possible to predict when an increase in expertise and communication competency would increase patient satisfaction and word of mouth recommendation. This is a crucial finding that would be of clinical importance.

For the unstandardized coefficients, the product for word of mouth communication was 0.500 . When the mediating variable weight was statistically controlled/taken into account, the direct effect of provider's communication competence as a determinant of patient satisfaction, was represented by 0.325 and 0.433 respectively. This implies that communication competence of the provider positively influenced the length of consultation, leading to greater satisfaction with the provider. The b coefficient, which represented the effects of the influence of the provider's communication competence on overall satisfaction, was 0.953 , and was statistically significant. Thus, an increase in the provider's communication competence could result in a fair amount of increase in patient satisfaction.
The patients, in general, reported that the providers had (i) clarity; (ii) advisory skills; (iii) listening skills, and (iv) ability to reassure patients. The patients also noted that the providers (could have, but) did not (i) engage in small talk and informal chat; (ii) cross question them; (iii) give additional information, and (iv) assist them in decision making on a possible course of action. Patients from rural areas asked fewer questions, and inclined to be greatly influenced by the controlling style the provider. Patients from urban areas were more articulate and expected the provider to reciprocate for long waiting times. These findings also reflect the findings of Roter (with respect to communication skills) and also of Flocke, Miller, and Crabtree. However, less consultation time was a determinant of low satisfaction contradicting the findings of Roter who had stated that consultation time did not affect patient satisfaction.

In terms of gender, the male provider influenced the male patients to a lesser extent, even as the male providers recorded less waiting time than female providers did. This is attributed to the fact that more number of illiterate patients and rural patients consulted the male providers, who in turn tend to exert a controlling communication style over these patients. This could possibly be the reason why male providers engaged less in advising, clarifying, soliciting information and giving support to assist patients in medical decisionmaking. In terms of dyadic communication, male providers were more empathetic with female patients, possibly because more urban females visited male providers

The research is important for providers for two reasons: first for the provider to understand the important role of communicating effectively with the patients. As patients get to be more technologically savvy and more urbanized, they 
start expecting better services from outpatient and primary care health centers. The second reason is tied up with the first-to understand the importance of giving adequate time to the patients. Currently providers are rushing from one nursing home or hospital to the other, ignoring the hope of addressing the requirements of the patients sitting in front of them. Providers need to be sensitized to the needs and wants of the patients (both rural and urban) and to revisit the service paradigm of healthcare profession

The research is not without its limitations. The first relates to the nature of the study. A cross sectional study does not always give a complete picture of the responses of the patients since it is conducted at a point of time; its validity therefore cannot be established fully. The second relates to the assessment of demographic variables on the results. While the mediation tests do control for gender, there are other demographic variables that could affect the findings. These include place of residencerural or urban, as well as education level of the patients.

Researchers interested in this field might like to explore the impact of consultation time in developed nations and compare the findings; they could also investigate issues relating to the impact of time in general-both consultation time as well as waiting time.

\section{References}

1. Maguire P, Pitceathly C. Key communication skills and how to acquire them. British Medical Journal 2002; 325: 697-700.

2. Piette JD, Heisler M, Wagner TH. Cost-related medication underuse among chronically ill adults: the treatments people forgo, how often, and who is at risk. American Journal of Public Health 2004; 94(10): 1782-1787.

3. Makaryus AN, Friedman EA. Patients' understanding of their treatment plans and diagnosis at discharge. In Mayo Clinic Proceedings. Elsevier 2008; 80 (8): 991-994.

4. Di Matteo MR. The role of the physician in the emerging health care environment. West J Med. 1998; 168 (5): 328-33.

5. Fortis Healthcare Ltd. Annual Report, http://www.fortishealthcare.com/pdf/Fortis_AR_20 13-14.pdf. 2014 (Accessed December 27, 2015).

6. Fong, JH, Anat, DS, Longnecker, N. Doctor-Patient Communication: A Review. Ochsner J. 2010; 10(1): 38-43.

7. Ben-Sira, Z, Affective and instrumental components in the physician-patient relationship: an additional dimension of interaction theory', Journal of Health and Social Behaviour 1980; 21, 2: 170-180.

8. Buller K, Buller D. Physicians' communication style and patient satisfaction. Journal of Health and Social Behaviour 1987; 28: 375-388.

9. Agarwal RK, Murinson, BB. New Dimensions in Patient-Physician Interaction: Values, Autonomy, and Medical Information in the Patient-Cantered Clinical Encounter. Rambam Maimonides Med J. 2012 Jul; 3(3): e0017 (PubMed)
10. Hausman A. Taking your medicine: Relational steps to improving patient compliance. Health Marketing Quarterly 2001; 19 (2): 49-71.

11. Zachariae R, Pedersen CG, Jensen AB, et al. Association of perceived physician communication style with patient satisfaction, distress, cancerrelated self-efficacy and perceived control over the disease. British Journal of Cancer 2003; 88(5): 65865.

12. Zoppi K, Epstein R. Is Communication a Skill? Family Medicine 2002; 319-324.

13. Fossum B, Arborelius E. Patient-centered communication: Videotaped consultations. Patient Education and Counselling 2004; 54(2): 163-9.

14. Roter $\mathrm{D}$. The enduring and evolving nature of the patient-physician relationship. Patient Education and Counselling 2000; 39 (1): 5-15.

15. Stewart M, Brown JB, Brown A, et al. The impact of patient-centered care on outcomes. The Journal of Family Practice 2000; 49 (9): 796-804.

16. Takayama T, Yamazaki Y. How breast cancer outpatients perceive mutual participation in patient-physician interactions. Patient education and Counselling 2004; 52(3): 279-289.

17. Kim SS, Kaplowitz S, Johnston MV. The effects of physician empathy on patient satisfaction and compliance. Evaluations and the Health Professions 2004; 27(3): 237-51.

18. Flocke SA, Miller WL, Crabtree BF. Relationships between physician practice style, patient satisfaction, and attributes of primary care. The Journal of Family Practice 2002; 51(10): 35-840.

19. Pirkko VS. Encounters in the health care: the voice of the patient. In Dissertations in Health Sciences. University of Eastern Finland 2011. 
20. Bensing JM, Van den Bruink-Muinen A, Bakker de. Gender differences in practice style: A Dutch study of general practitioners Medical Care, 1993; (3): 219-229. (Pub Med).

21. Boulis AK, Jacobs JA. An analysis of the impact of gender on physician practice patterns. Journal of Health \& Social Policy 2003; 18(1): 57-87.

22. Sans-Corrales M, Pujol-Ribera E, Gené-Badia J, et al. Family medicine attributes related to satisfaction, health and costs. Family Practice 2006; 23 (3): 308316.

23. Howie GR, Heaney D, Maxwell M. Quality, core values and the general practice consultation: Issues of definition, measurement and delivery. Family Practice 2004; 21(4): 458-468.

24. Anderson RT, Camacho FT, Balkrishnan R. Willing to wait? The influence of patient waits time on satisfaction with primary care. BMC Health Services Research 2007; 7: 31.

25. Buller K, Buller D. Physicians' communication style and patient satisfaction. Journal of Health and Social Behavior 1987; 28: 375-388.

26. Hair JF, Hult GT, Ringle $M$, et al. A primer on partial least squares structural equation modelling (PLS SEM). Thousand Oaks, CA: Sage Publications 2014.

27. Nunnally JC, Berstein IH. Psychometric theory. 3rd Edition. New York: McGraw Hill; 1994.

28. Baron, Reuben M., and David A. Kenny. The moderator-mediator variable distinction in social psychological research: Conceptual, strategic, and statistical considerations. Journal of personality and social psychology 1986; 51.6: 1173.

\section{DECLARATIONS}

\section{Ethics and Consent to Participate}

This research work was carried out in consonance with the seed money guidelines issued by the institution, viz., IIM Lucknow, INDIA. The awarding body is known as the 'Research Committee' and it is charged with the authority to issue statement of consent for conducting the study involving human participants and also with the consent to publish

\section{Name of Ethics committee present}

The Ethics committee is known as the 'Research Committee' in the institute. It is the approving body for faculty seed money grants This project was under the aegis of the seed money scheme for Participating faculty (No: SM-197)

\section{Competing Interest}

There are no competing interests to report

\section{Author's contributions}

This submission is submitted by a single author

\section{Availability of data and materials}

The supporting materials are embedded in the files submitted in the Editorial Manager. The file is labelled as 'Datasets'

\section{Informed consent}

Informed consent was obtained from all individual participants included in the study. Formal permission was taken from all the providers it the Outpatient clinics

\section{Acknowledgments}

I am grateful to my organization, IIM Lucknow for sponsoring the project under the seed money scheme for Participating faculty (SM-197) 